\title{
'THE LIKENESS OF MY MOTHER AND SISTER': OPNIEUW EEN AANWINST UIT DE COLLECTIE VAN BRAAM HOUCKGEEST
}

In 2003 verwierf het Rijksmuseum een interessante groep Chinese voorwerpen uit de verzameling van Andreas Everardus van Braam Houckgeest (1739-1801). ' Van Braam was jarenlang koopman voor de VOC in China geweest en hij was - veel meer dan zijn vele collega-kooplieden - zeer geïnteresseerd in het Chinese keizerrijk. Hij nam op persoonlijke titel deel aan de ambassade naar het Chinese hof in 1794-95 om meer van het land te kunnen zien dan de speciale buitenwijk voor westerlingen in Kanton, publiceerde over deze reis en legde een imposante verzameling Chinese voorwerpen aan.

\section{Een bijzonder bruikleen}

Sinds dit najaar is in het museum 'de Van Braam-groep' uitgebreid met een bijzonder bruikleen: een prachtige en beroemde achterglasschildering (afb. 1). Dit is een van de laatste objecten uit de beroemde Van Braam-verzameling die nog in particuliere handen is en zonder twijfel het belangrijkste. ${ }^{2}$ Het stelt een moeder en dochter voor, beiden in op de klassieke oudheid geënte gewaden, die buiten voor een boom op een bank zitten.

Omdat het schilderij ononderbroken in familiebezit is gebleven, is het zonder twijfel in verband te brengen met een omschrijving in een handgeschreven verklaring van Van Braams oudste dochter Everarda waarin ze kort voor haar dood haar persoonlijke spullen verdeelt onder haar naasten: 'To Maria the picture containing the likeness of my mother and sister', schreef $z \mathrm{ij},{ }^{3}$ en hiermee wordt duidelijk wie er zijn afgebeeld. Aangezien Everarda Van Braams dochter is, moet 'My mother' Van Braams vrouw zijn, Catharina Geertruida van Reede van Oudtshoorn (1746-1799). 'Sister' kan alleen Françoise Constantia Carolina Maria zijn. Zij was in 1785 geboren en de enige zuster van Everarda. Deze Françoise was Van Braams jongste kind en ze was nog maar vier jaar oud toen haar vader voor de laatste keer voor een verblijf van enige jaren naar China vertrok. In China bestelde Van Braam deze misschien wat zoetige, maar toch ook innemende en in elk geval razend knap gemaakte schildering. Het stelt het gezin voor dat hij achterliet en dat enige jaren daarvóór nog een stuk groter was geweest. Zijn oudste dochter was getrouwd en uit huis, de vier daarop volgende kinderen waren omgekomen bij een difterie epidemie in South-Carolina in de Verenigde Staten, waar de familie in de jaren ' 80 van de 18 e eeuw woonde. Zijn vrouw, jongste dochtertje en hijzelf hadden de epidemie overleefd, maar zaten financieel zo aan de grond dat Van Braam op zijn relatief oude dag opnieuw naar China moest om geld te verdienen. In de periode 1790-1795 heeft hij dat met veel succes gedaan. 


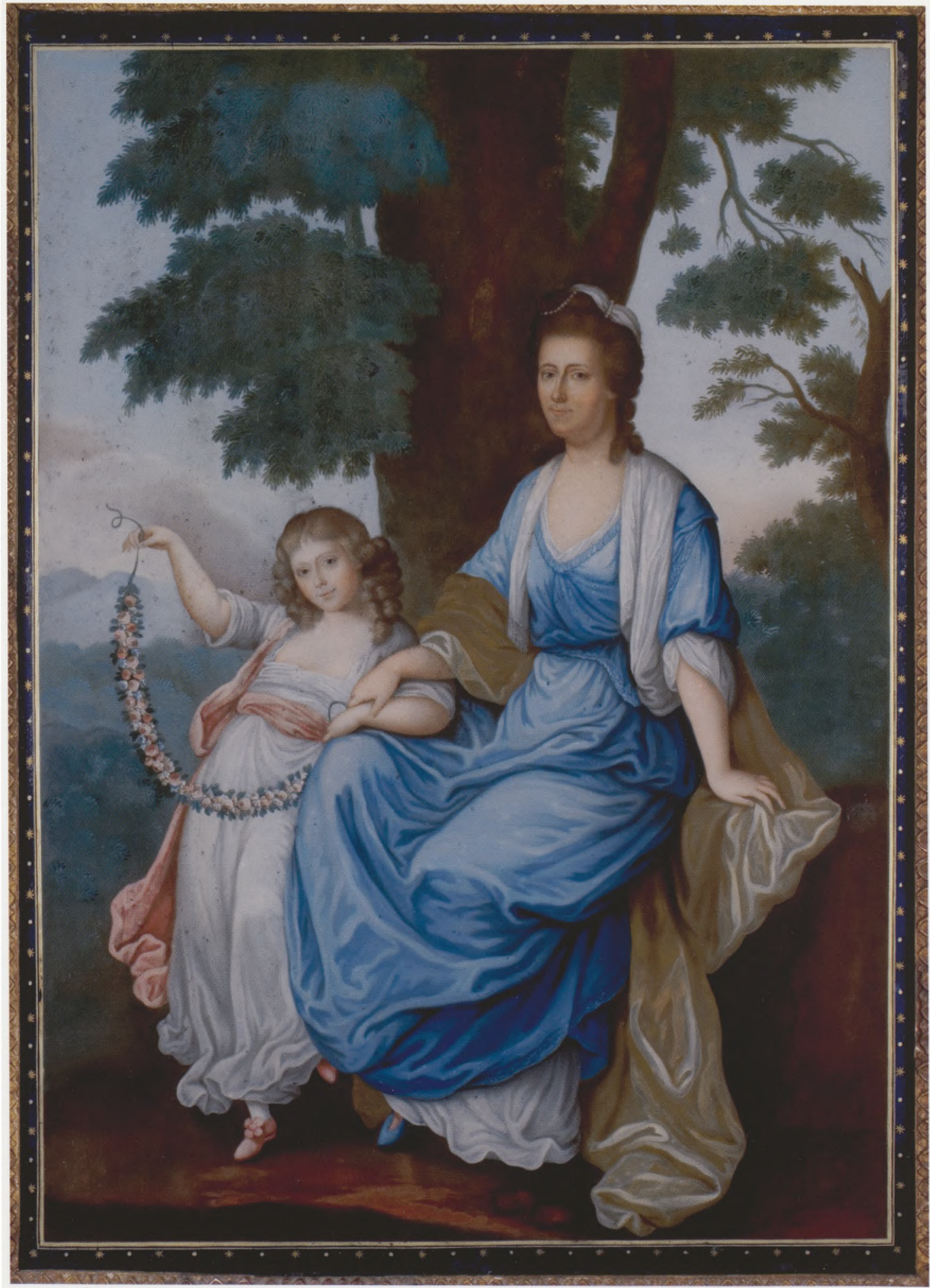




\section{Afbeelding 1 (links) \\ Catharina van Braam Houckgeest en haar dochter Françoise, achterglasschildering, Kanton, 1795, 63,5 X 49 cm., bruikleen Koning Boudewijn Stichting, schenking Margaret C. Elliott, Media, Pennsylvania.}

\section{Afbeelding 2} Stippelgravure naar een prent van Thomas Burke, Lady Rushout and her daughter Anne, Rijksprentenkabinet, Amsterdam.

\section{Bestelling in Kanton}

Het zal geen probleem zijn geweest dit schilderij te bestellen. Chinese schilders in Kanton werkten in deze periode zeer dikwijls in Europese stijl, zowel in opdracht als 'voor de markt'. ${ }^{4}$

Prenten dienden als voorbeeld en naar wens konden verschillende voorbeelden gecombineerd worden tot een eigen ontwerp. Een kunstenares die in Europa aan het eind van de $18 \mathrm{e}$ eeuw bijzonder geliefd was, speciaal ook door de vele prenten die naar haar werk werden gemaakt, was Angelika Kauffman (1741-1807). In het laatste kwart van de achttiende eeuw was het plotseling in de mode geraakt om prenten in te lijsten en aan de muur te hangen (in plaats van ze te bewaren in portefeuilles). Kauffman was in deze mode de populairste kunstenaar en zij schilderde zelfs speciaal met het doel haar werk in prent te laten uitbrengen en verkopen. ${ }^{5}$ Vaak, maar zoals zal blijken niet altijd, zijn het mythologische of allegorische voorstellingen, of illustraties van verhalen of gedichten. De mode drong ook snel door tot in Kanton. Het dubbelportret van de dames Van Braam blijkt vrijwel volledig te zijn gebaseerd op een schilderij van Kauffman uit 1773, Lady Rushout and her Daughter, Anne. ${ }^{6}$ De stippelgravure die Thomas Burke (1749-1815) ervan maakte werd in 1784 uitgegeven. Het werk van Burke was zo populair dat

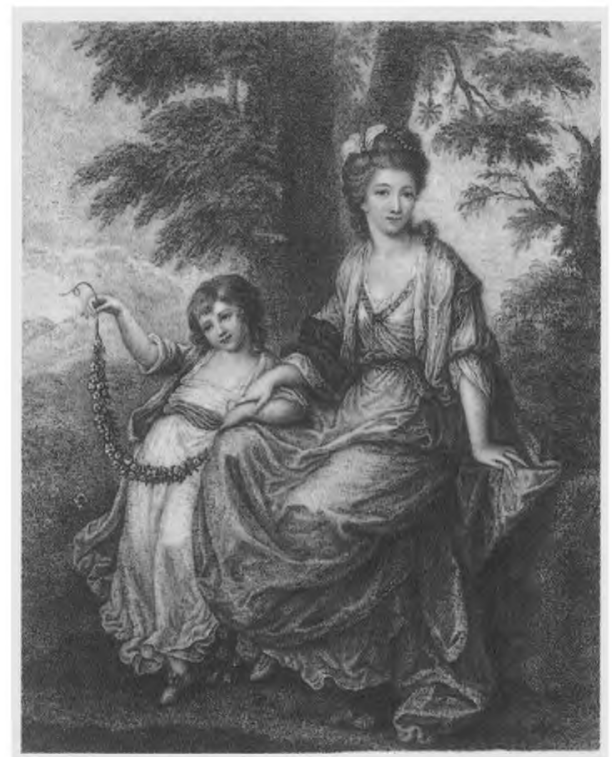

ook hiervan weer kopieën in omloop werden gebracht. Blijkbaar was enkele jaren na de verschijning de prent of de kopie aanwezig in Kanton (afb. 2). ${ }^{7}$ Het enige element dat wezenlijk verschilt, is het gezicht van mevrouw Van Braam. Hiervoor gebruikte de schilder een ander voorbeeld, misschien een medaillon of een andere schildering die Van Braam met zich mee op reis had genomen. Hoogstwaarschijnlijk is het hetzelfde voorbeeld dat diende in een andere schildering die hij bestelde en die zijn vrouw voorstelt 'gedragen' door een allegorische voorstelling van de Hoop (afb. 3). Alleen het gezicht is in het dubbelportret aangepast; het haar is weer gebaseerd op de prent van Burke. Weliswaar moest de schilder dit vanwegende stand van het gezicht in 23 11:21:09pM 

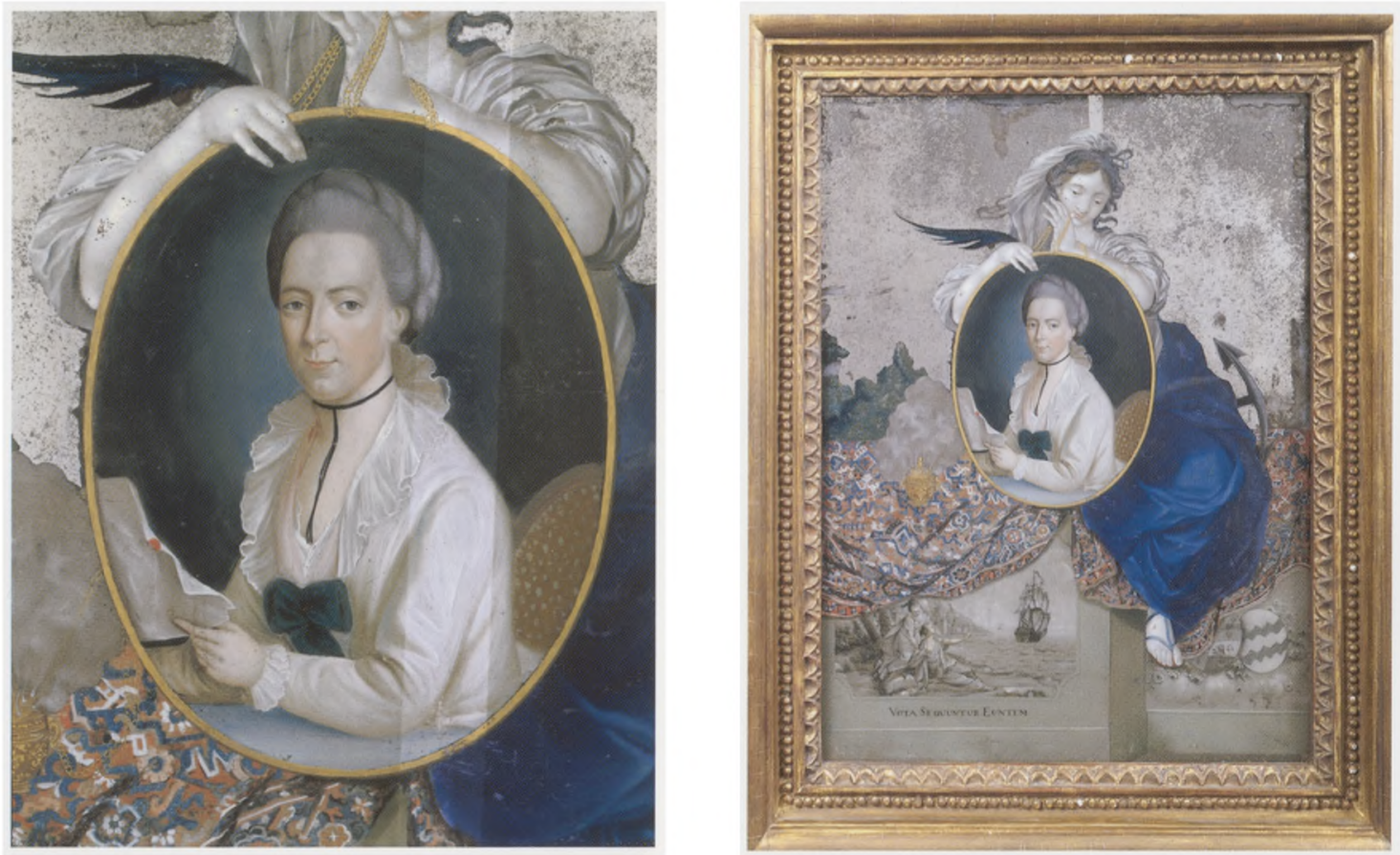

Afbeelding 3a (links) Catharina 'gedragen door Hoop', achterglasschildering, Kanton, ca. 1790, 55,4 X 45,2 cm., Rijksmuseum Amsterdam, inv.nr. AK-RAK2003-7.

\section{Afbeelding 3b} Detail uit de schildering $3 a$ spiegelbeeld weergeven, maar dat was geen probleem. Van veel voorbeeldprenten werden goedkope kopieën gemaakt door ze over te trekken en de nog natte inkt op een ander blad (in spiegelbeeld) af te drukken. Zo beschikten de Chinese schilders vaak over 'originele' en gespiegelde voorbeelden.

Opmerkelijk is dat het meisje niet aan de actualiteit is aangepast. Blijkbaar had Van Braam van haar geen afbeelding bij zich. Aangezien het meisje eerder tien dan vijf jaar oud is, lijkt het me waarschijnlijk dat Van Braam dit schilderij besteld heeft kort voordat hij China in 1795 verliet. Van Braam zal zich gerealiseerd hebben dat zijn dochter op dat moment bij benadering de leeftijd van Kauffmans Anne had. Bovendien bestelde hij de meeste van de objecten, meubelen en kunstwerken die hij naar huis meenam, vlak voor zijn vertrek. Hij zal de schildering als souvenir voor thuis bedoeld hebben.

\section{Europese prenten als model}

Een interessante, maar niet te beantwoorden vraag is wie de prent geleverd heeft. Was dat Van Braam en lag het regie voor de vervaardiging van dit portret geheel bij hem? Of had het atelier voorraden prenten waaruit klanten konden kiezen? Tot nog toe zijn mij geen andere Chinese schilderingen bekend naar deze voorbeeldprent, een aanwijzing dat Van Braam met de prent naar het atelier is gegaan, de kleine aanpassing bedacht heeft en de schildering exclusief voor zichzelf heeft laten maken. Het idee zijn vrouw in de kleding en de entourage van een Engelse lady af te laten beelden past geheel in Van Braams doorlopende poging om zich te ${ }^{3}$ presentereñ als een : $^{21: 09 \mathrm{pM}}$ 


\author{
Afbeelding 4 \\ Waaier, ivoor, deels \\ beschilderd, Kanton, \\ ca. 1795, breedte $37 \mathrm{~cm}$., \\ Rijksmuseum Amster- \\ dam, inv.nr. AK-RAK- \\ 2003-9
}

aanzienlijk heer en erkenning te vinden bij zijn omgeving voor zijn positie. Ander Chinees werk naar Kauffman is wel degelijk bekend. In het kielzog van het onderzoek naar het voorbeeld dat aan dit schilderij ten grondslag lag, kon ook worden vastgesteld welke prent gebruikt werd om het centrale medaillon te schilderen op een waaier die Van Braam in Kanton kocht en die het Rijksmuseum in 2003 verwierf (afb. 4). Het blijkt een scène te zijn uit het gedicht Henry and Emma van Matthew Prior (1664-1721), een scène die door Angelika Kauffman werd geschilderd en (pas!) in 1792 in de vorm van een stippelgravure door Burke werd uitgegeven (afb. 5). ${ }^{8}$ Drie jaar later kon Van Braam al een waaier kopen met deze voorstelling; Kanton volgde de mode op de voet. Interessant is ook om vast te stellen dat deze prent pas werd uitgegeven ná Van Braams vertrek naar China. De mogelijkheid dat hij prenten van huis mee had genomen en als voorbeeld aan Chinese schilders gaf, kan in dit geval dus uitgesloten worden.

Zoals velen moet Van Braam van het werk van Kauffman gehouden hebben. In twee afzonderlijke beschrijvingen van zijn collectie wordt met name het Chinees werk naar Kauffman vermeld: in de veilingcatalogus van zijn collectie en in het reisverslag van een bezoeker. In de catalogus van de veiling (veel van Van Braams collectie moest door geldnood in 1799 worden verkocht) staat: 'Venus attired by the Graces, from Angelica Kauffman'. ${ }^{9}$ Verschillende prenten met Venus in een hoofd- of bijrol naar Kauffman zijn bekend, maar wat hier precies bedoeld is, blijft nog onduidelijk. Evenmin is

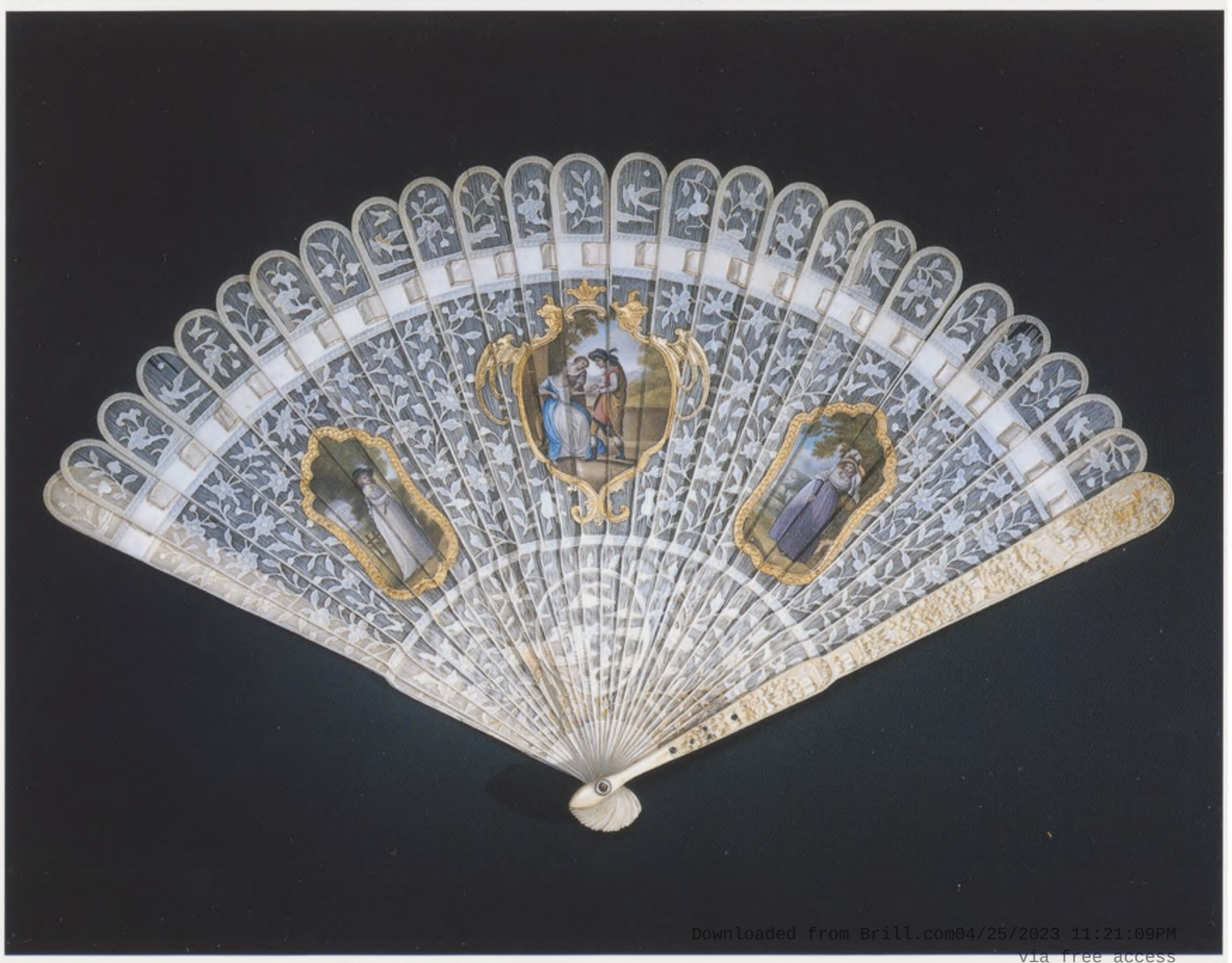




\section{Afbeelding 5 \\ 'Henry and Emma', stippelgravure door Thomas Burke, 1792, Rijksprentenkabinet, Amsterdam.}

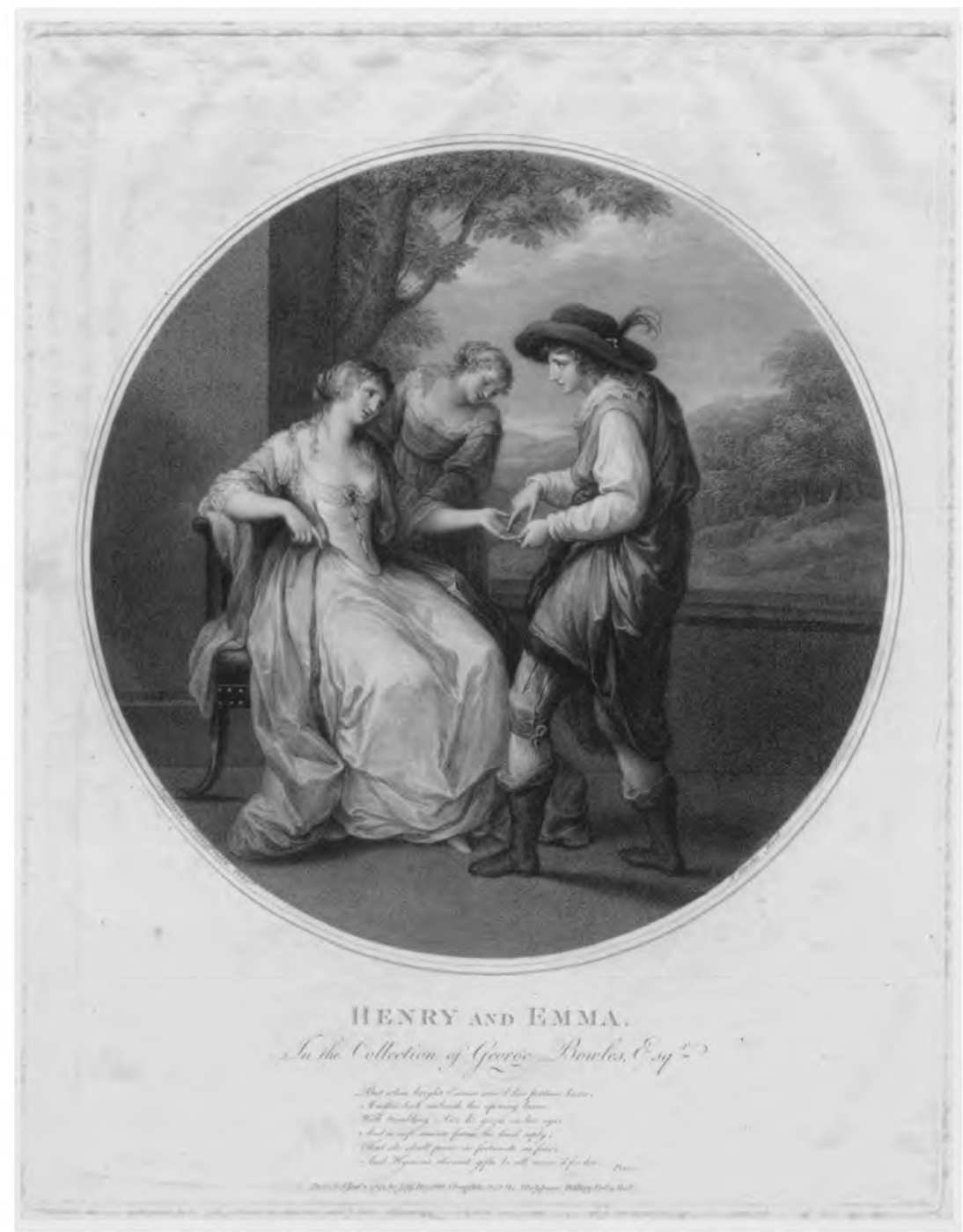

uit de beschrijving op te maken of het een achterglasschildering betreft of een schildering op doek. De Poolse reiziger Julian Ursyn Niemcewicz (1757-1841) bezocht Van Braam in 1798 en roemde in zijn reisverslag de collectie. Hij vermeldt het grote aantal schilderingen naar Westerse voorbeelden, maar noemt alleen de namen van Titiaan en Angelika Kauffman. ${ }^{10}$

\section{Achterglasschilderingen in China}

De bijzondere techniek waarin het schilderij is gemaakt - het achterglasschilderen - verdient nog een korte toelichting. Vanaf de jaren ' 40 van de 18e eeuw werden geregeld achterglasschilderingen als souvenir uit China meegenomen. ${ }^{11}$ Zowel Chinese voorstellingen (aangepast aan de Westerse smaak en verwachtingen) als Europese voorstellingen komen voor.

De fijnheid van het schilderwerk en de criante moeilijkheid van de techniek zullen de westerlingen hebben aangesproken. Want behalve het vermogen om naar Europese voorbeelden te werken, bestondersin Europa ân de $18 \mathrm{e}$ : 21: 09pM 
eeuw bewondering voor de grote vaardigheid van het handwerk van de Chinezen. Het uiterst fijne snijwerk in de waaier werd zeer gewaardeerd en hetzelfde geldt voor het schilderen achter glas. Een Engelse reiziger, William Hickeley (ca.1749-1830), werd bij zijn bezoek aan Kanton direct meegenomen om 'the celebrated painters upon glass' te bewonderen. ${ }^{12} \mathrm{Zij}$ waren blijkbaar een vermaarde attractie. Hoewel in China zelf glas werd geproduceerd, gebruikten de schilders vlak glas van betere kwaliteit dat vanuit Engeland werd ingevoerd. De kleuren moeten zoveel mogelijk naast elkaar en niet over elkaar worden aangebracht en een correctie door overschildering is onmogelijk. ${ }^{13}$ Onderzoek naar de achterglasschilderingen in de collectie van het Leidse Rijksmuseum voor Volkenkunde wees uit dat allereerst op de voorzijde van het glas in inkt de contouren werden geschilderd, die bij het vervolg van het werk houvast gaven. Restanten van deze lijnen waren bij de Leidse schilderingen nog te zien op de plek waar oorspronkelijk de lijst had gezeten. ${ }^{14}$ De schilderingen werden ingelijst uitgevoerd om ze tegen breuk te beschermen en dikwijls zijn deze lijsten nog aanwezig. Helaas geldt dat niet voor het portret van mevrouw Van Braam en haar dochter. Enige vorm van schilderen op glas moet in China zelf gebruikelijk zijn geweest. Isaac Titsingh (1745-1812), de leider van de ambassade naar Peking waaraan ook Van Braam deelnam, vermeldde in het verslag van zijn terugreis van Peking naar Kanton dat hij van 23 op 24 februari de nacht doorbracht in het huis van een mandarijn dat zijn gezelschap ter beschikking werd gesteld en dat hier in het slaapvertrek 'doorscheinende schilderijen op glas' hingen. ${ }^{15}$ Dit was in het binnenland van China, ver van de invloed van Peking of Kanton. Toch wordt over het algemeen aangenomen dat de techniek afkomstig is uit Europa, waar het achterglasschilderen in de $16 e$ eeuw al op verschillende plaatsen werd beoefend. Wellicht brachten missionarissen de techniek naar Peking, maar er zijn ook aanwijzingen dat het achterglasschilderen het eerst in Kanton werd toegepast en via Kanton in Peking bekend werd. De geleerde jezuietenmissionaris Pierre-Martial Cibot (1727-1780) schreef in zijn artikel over het achterglasschilderen in de Mémoires concernant l'histoire, les sciences, les arts, les moeurs, les usages (...) des Chinois dat Kantonese [mijn cursivering] schilders in Peking deze kunst beoefenden en dat het voor hem iets geheel nieuws was. ${ }^{16}$ Wel merkte hij op dat het 'echte werk' in Peking werd gemaakt, en deed hij het schilderwerk in Kanton af als 'un métier qui ne demande que des ouvriers'. ${ }^{17}$ Dat het dédain voor het werk van de Kantonese schilders niet geheel terecht is, blijkt uit de kwaliteit van Van Braams dubbelportret.

\section{Noten}

1. Zie de aankondiging in dit blad 34/1 (2004) en een artikel te verschijnen in het Bulletin van het Rijksmuseum 53/1 (2005), pp. 18-41.

2. Gepubliceerd in I. G. Lee, Philadelphians and the China Trade 1784-1844 (tent.cat. Philadelphia Museum of Art) Philadelphia, 1984, nr. 47 en C.L. Crossman, The Decorative Arts of the China Trade; painting, furnishings and exotic curiosities, Woodbridge, 1991, colour plate 4.

3. Memorandum in het bezit van de Amerikaanse nazaten van Van Braam. Met dank aan Kee Il Choi, New York, voor het afschrift.

4. George Staunton (1737-1801) en John Barrow (1764-1848), beide lid van een Engelse ambassade naar het Chinese hof in 1793 en schrijvers van verslagen van deze reis, merkten op hoe goed de Chinese schilders Europees werk konden kopiëren. 'In Canton artists are uncommonly expert in imitating European works (...) they copy paintings and coloured drawingsowith great success.' (Staunton) fon: 11:21:09pM 
'Coloured prints of Europe that are carried to Canton are copied there with the most wonderful fidelity.' (Barrow). Beide citaten zijn overgenomen uit G. Child, World mirrors, Londen, 1990, pp. 364 en 385.

5. D. Alexander, 'Kauffman and the Print Market in Eighteenth-century England', in: W.W. Roworth (red.), Angelika Kauffman; a continental artist in Georgian England, Brighton/Londen, 1992, pp. 141-178.

6. Ik ben Robert Jan te Rijdt, Rijksprentenkabinet Amsterdam veel dank verschuldigd voor deze vondst. Voor een afbeelding zie Roworth, op.cit., afb. 82.

7. Roworth, op.cit., p. 185, nr. 189. F. O'Donoghue, Catalogue of engraved British portraits presenved in the department of prints and drawings in the British Museum, Londen, 1912, deel III, p. 355.

8. Roworth, op.cit., p. 188, nr. 274; D. Alexander, Affecting moments; prints of English literature made in the age of romantic sensibility, 1775-1800 (tent.cat.), York, 1993, nr. 21.

9. Voor de veilingcatalogus zie J.J.L Duyvendak, 'The last Dutch embassy to the Chinese court (1794-1795)', Toung Pao 34 (1938), pp. 116-131, de Kauffman kopie is nr. 44. Hier 56 schilderingen genoemd, waarvan 35 naar Europese (vooral Franse) prenten, 14 met een Chinees onderwerp en 7 waarvan niets over het Chinese of Europese karakter valt te zeggen; in slechts één geval wordt expliciet een schildering op glas genoemd (nr. 56 la mère bien aimée, waarschijnlijk naar een pastel van Jean Baptiste Greuze (1725-1805) die onder die naam bekend is. De groep schilderingen wordt aangeprezen als 'entirely executed by Chinese Artists, with a singular Degree of Delicacy and Finishing, and are beautiful Specimens of the Progress of the fine Arts in China.' De vooruitgang van de kunsten in China zijn - zo wordt gesuggereerd - af te meten aan het vermogen van de Chinese schilders in de westerse stijl te werken en te kopiëren.

10. Passages uit het reisverslag worden geciteerd in E.R. Barnsley. The first VBH; twovolume biography about the remarkable life of an eighteenth century Dutch citizen and naturalized American named Andreas Everardus van Braam Houckgeest, Beach Haven (N.J.), 1989-1991, deel I, p. 175.

11. Child, op.cit., p. 363.

12. Geciteerd in Child, op.cit., p. 364.

13. P. van Dongen, "Sensitive Plates"; nineteen Chinese paintings on Glass from the end of the eighteenth century', Archiv für Völkerkunde (Museum für Völkerkunde Wien) 49 (1995), p. 78.

14. Van Dongen, op.cit., p. 78.

15. F. Lequin, lsaac Titsingh in China (1794-1796); het onuitgegeven Journaal van zijn Ambassade naar Peking, Alphen aan den Rijn, 2005, p. 156-157.

16. Van Dongen, Op.cit., p. 75.

17. Geciteerd door Van Dongen, Op.cit., p. 77. 